ఠ

REVIEW

\title{
Prevalence and severity of pain in adult end-stage renal disease patients on chronic intermittent hemodialysis: a systematic review
}

This article was published in the following Dove Press journal:

Patient Preference and Adherence

23 June 2016

Number of times this article has been viewed

\section{Tonci Brkovic' \\ Eliana Burilovic ${ }^{2}$ \\ Livia Puljak ${ }^{3}$}

'Department of Internal Medicine, Division of Nephrology, ${ }^{2}$ Department of Psychiatry, University Hospital Split, ${ }^{3}$ Department of Anatomy, Histology and Embryology, Laboratory for Pain Research, University of Split School of Medicine, Split, Croatia
Correspondence: Livia Puljak Laboratory for Pain Research, University of Split School of Medicine, Šoltanska 2, 21000 Split, Croatia

Tel +385 2l 557807

Fax+385 21 557811

Email livia@mefst.hr
Objectives: Understanding the epidemiology of pain in patients on hemodialysis (HD) is crucial for further improvement in managing pain. The aim of this study was to systematically review available evidence on the prevalence and severity of pain in adult end-stage renal disease patients on chronic intermittent HD.

Materials and methods: We carried out a systematic review of the literature and developed a comprehensive search strategy based on search terms on pain and HD. We searched the databases MEDLINE, Scopus, PsycINFO, and CINAHL from the earliest date of each database to July 24, 2014. Manuscripts in all languages were taken into consideration. Two authors performed each step independently, and all disagreements were resolved after discussion with the third author. The quality of studies was estimated using the STROBE checklist and Cochrane risk-of-bias tool.

Results: We included 52 studies with 6,917 participants. The prevalence of acute and chronic pain in HD patients was up to $82 \%$ and $92 \%$, respectively. A considerable number of patients suffered from severe pain. Various locations and causes of pain were described, with most of the studies reporting pain in general, pain related to arteriovenous access, headache, and musculoskeletal pain.

Conclusion: The findings of this systematic review indicate high prevalence of pain in HD patients and considerable gaps and limitations in the available evidence. Pain in this population should be recognized as a considerable health concern, and the nephrology community should promote pain management in HD patients as a clinical and research priority to improve patients' quality of life and pain-related disability.

Keywords: pain, hemodialysis, prevalence, intensity, epidemiology

\section{Introduction}

The prevalence of chronic kidney disease is increasing worldwide, and is expected to continue increasing. ${ }^{1}$ There are five stages of chronic kidney disease, with endstage renal disease (ESRD) its final stage. With worsening of their kidney disease, patients develop many complications associated with a high risk of comorbidities and mortality. ${ }^{2-4}$ Therefore, health care professionals caring for ESRD patients should aim not only to extend patients' life span but also improve their quality of life. ${ }^{5}$ ESRD patients of all ages also have poor quality of life. ${ }^{6-8}$ One of the most important qualitative parameters for evaluating patients' quality of life is bodily pain. ${ }^{9}$ Therefore, it is important to understand and relieve bodily pain in this population, in order to improve their quality of life and quality of care.

ESRD is defined as loss of renal function requiring renal replacement therapy with any form of chronic dialysis or transplantation or occasionally conservative 
management in the elderly or those with significant comorbidities. ${ }^{10-12}$ Incidentally, acute kidney injury requiring dialysis is not considered ESRD unless renal function fails to recover. ${ }^{13}$

Pain is common in ESRD patients. ${ }^{14}$ Based on data from surveys, when asked, up to $50 \%-60 \%$ of dialysis patients admit to feeling pain, often very severe and not effectively managed, although many will not mention this to their doctors at clinic visits. ${ }^{14,15}$ Pain is the major cause of depression, disturbed sleep patterns, impaired dialysis adequacy (if unable to endure full sessions), and likeliness of withdrawal from dialysis. ${ }^{16}$

Therefore, the objectives of this systematic review were to provide an updated analysis of epidemiological studies on pain in patients on hemodialysis (HD), to use both systematic and narrative methods to provide an objective summary of the literature, to assess study quality, and to provide recommendations for practice and research. Understanding the epidemiology of pain in patients on HD is crucial for further improvements in managing pain.

\section{Materials and methods}

A systematic review of literature was carried out in accordance with the guidelines of the Center for Reviews and Dissemination ${ }^{17}$ and the MOOSE study. ${ }^{18}$ A priori protocol of the systematic review was designed and registered in the PROSPERO database (registration number CRD42015024894).

\section{Inclusion/exclusion criteria}

We included all studies that reported epidemiology of pain in HD patients. Case reports and interventional studies reporting the effectiveness of interventions for the treatment of pain, as well as studies concerning peritoneal dialysis patients, continuous dialysis procedures, any other non-HD renal replacement therapy (eg, renal transplantation), plasmapheresis, children as participants and psychological studies concerning HD pain, were not included.

\section{Search strategy and record screening}

The databases MEDLINE, Scopus, PsycINFO, and CINAHL were searched from the earliest date of each database to July 24, 2014, with the help of a library information specialist. The complex search strategy was initially designed for MEDLINE (Table 1), and was then thoroughly adapted for each database. There were no publication type limits. Studies in any language were considered. The search results were exported to the EndNote X7.4 program (Thomson Reuters,
Table I MEDLINE search strategy

I) (h?emodialy $\$$ or h?emo $\$$ filtrat $\$$ or ultrafiltrat $\$$ ).tw

2) exp Renal Dialysis/or exp Hemofiltration/or exp Hemodiafiltration/ or $\exp$ Ultrafiltration

3) 1 or 2

4) (pain $\$$ or dolo?r or hurt $\$$ or ache or aching or pang? or $\$$ algia or \$dynia or discomfort or nocicept\$ or analge $\$$ or an? esthe $\$$ or pain?kill\$ or antihyperalg $\$$ or algesi $\$$ or anguish $\$$ or suffer $\$$ ).tw

5) $\exp$ Pain/ or exp Nociception/ or exp Analgesia/ or exp Anesthesia/ or exp Anesthetics/ or exp Analgesics/ or exp Stress, Psychological/ or exp Stress, Physiological/

6) 4 or 5

7) 3 and 6

New York, NY, USA), and duplicates were removed. Titles and abstracts of records retrieved by bibliographic search were initially screened by two authors (TB and EB) independently. Disagreements were resolved by the third author (LP). Once agreement was reached, the full text of each potentially eligible study was retrieved and analyzed by two authors independently. References and citations of included studies were downloaded from the Web of Science and screened by two authors independently (TB and EB) to identify additional citations that may have been missed through electronic database-search methods.

\section{Data extraction}

A data-extraction form was designed specifically for the study, and piloted and applied to all patients treated with HD without separation of individual subgroups. The following data were extracted: type of study, manuscript language, country, number of patients, age, sex, and race/ethnicity of patients, time of HD, type of pain studied, time recall for pain assessment, prevalence of pain, causes of pain, pain-intensity measuring tool, and pain-intensity results.

\section{Assessment of study quality}

STROBE checklist was used ${ }^{19}$ for assessing the quality of observational studies, where each of the 22 points of the STROBE criteria was assigned equal weight, and a total score was calculated. The Cochrane risk-of-bias tool was used $^{20}$ for randomized controlled trials.

\section{Results \\ Search results}

The database search yielded a total of 16,057 (MEDLINE 8,907, Scopus 6,639, CINAHL 425, PsycINFO 86) records. Based on the screening, the authors assessed that 63 full-text studies could contain relevant data. Analysis of full texts indicated 
that a total of 52 studies met our a priori inclusion criteria and were included in this review (Figure 1). Characteristics of included studies are presented in Table 2. The aim of the current review was to summarize epidemiological findings, and thus the summary of data using meta-analysis was not conducted. The findings were synthesized and described systematically.

\section{Excluded studies}

Eleven studies were excluded for various reasons: reporting headache and cramps as number and percentage of sessions with the clinical event without specifying number of affected patients, ${ }^{21}$ reporting prevalence of various handicaps of HD patients, but no information about pain prevalence; ${ }^{22}$ not presenting results separately for patients on different types of dialysis; ${ }^{23}$ seven were interventional studies with no data on baseline prevalence of pain; ${ }^{24-30}$ and one was a case report. ${ }^{31}$

\section{Included studies}

A total of 52 studies with 6,917 patients (range 15-591) were included. Studies were grouped according to the type of pain investigated, including prevalence of pain in general, prevalence by location, including pain related to arteriovenous (AV) access, headache, limb pain, chest pain, abdominal pain, and "other and procedural" pain, as well as such causes of pain as musculoskeletal pain, ischemic pain, and neuropathic pain.

A total of 49 studies were observational, including one letter to the editor, which contained original data that were extracted. ${ }^{32}$ Data about baseline pain prevalence were extracted from three interventional studies as well. ${ }^{33-35}$ All studies were published in peer-reviewed journals except one, which was freely available on an institution's Web site. ${ }^{35}$

Included studies were published between 1972 and 2014, and 39 of them were published in English. Studies were published in French, ${ }^{35-37}$ Italian, ${ }^{38}$ Portuguese, ${ }^{39,40}$ Serbian, ${ }^{41,42}$ and Spanish. ${ }^{4-47}$ Studies were conducted mainly in Europe and North America (Table 2), while the remaining studies were conducted in South America, ${ }^{21,25,39,48-51}$ Asia, ${ }^{33,52-54}$ and Africa. ${ }^{24,37}$ Distribution of age, ratio of male to female, and time on HD were very heterogeneous between the studies (Table 2). Race/ethnicity of patients was reported by only 13 studies (Table 2).

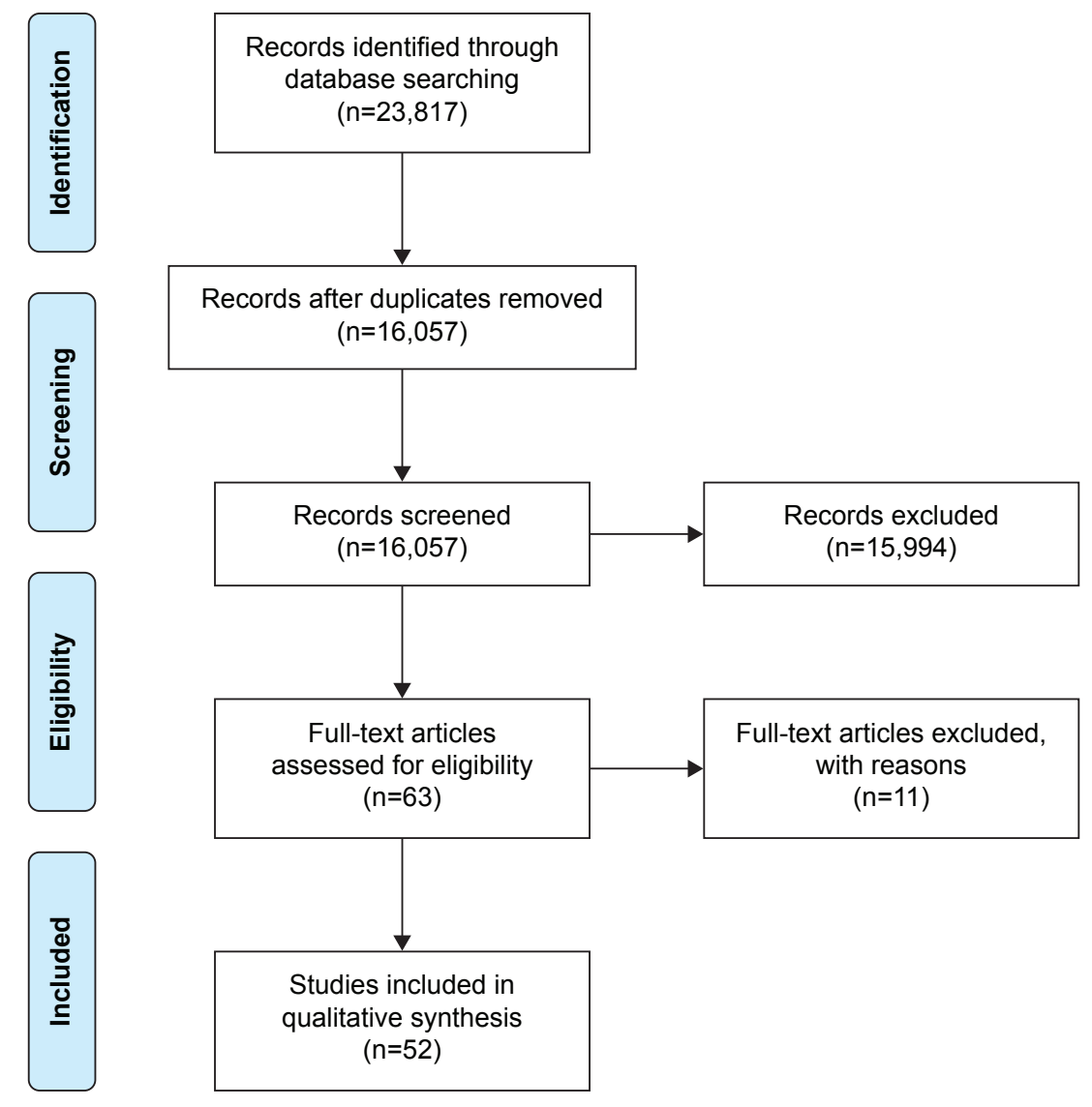

Figure I Study flow diagram. 


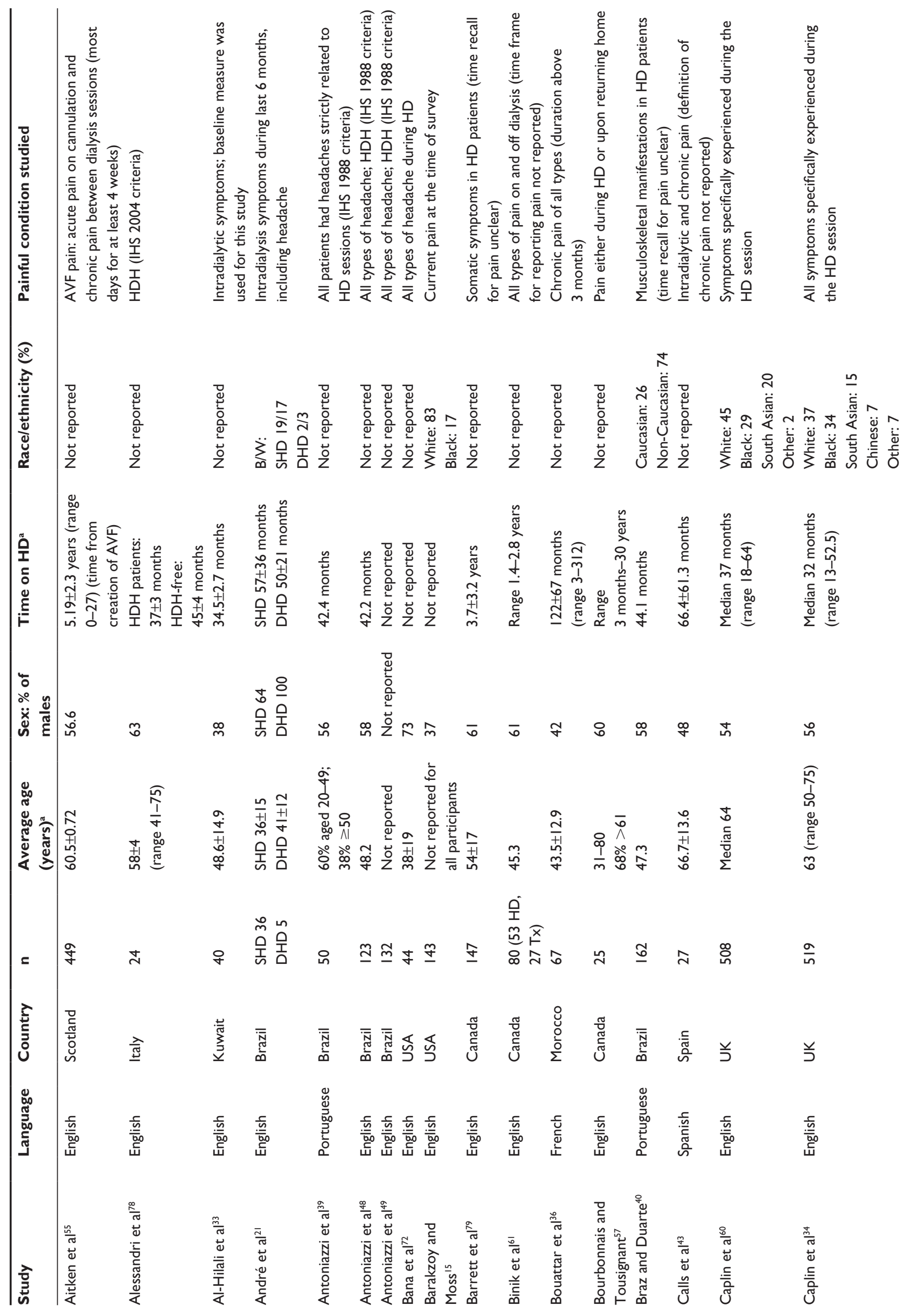




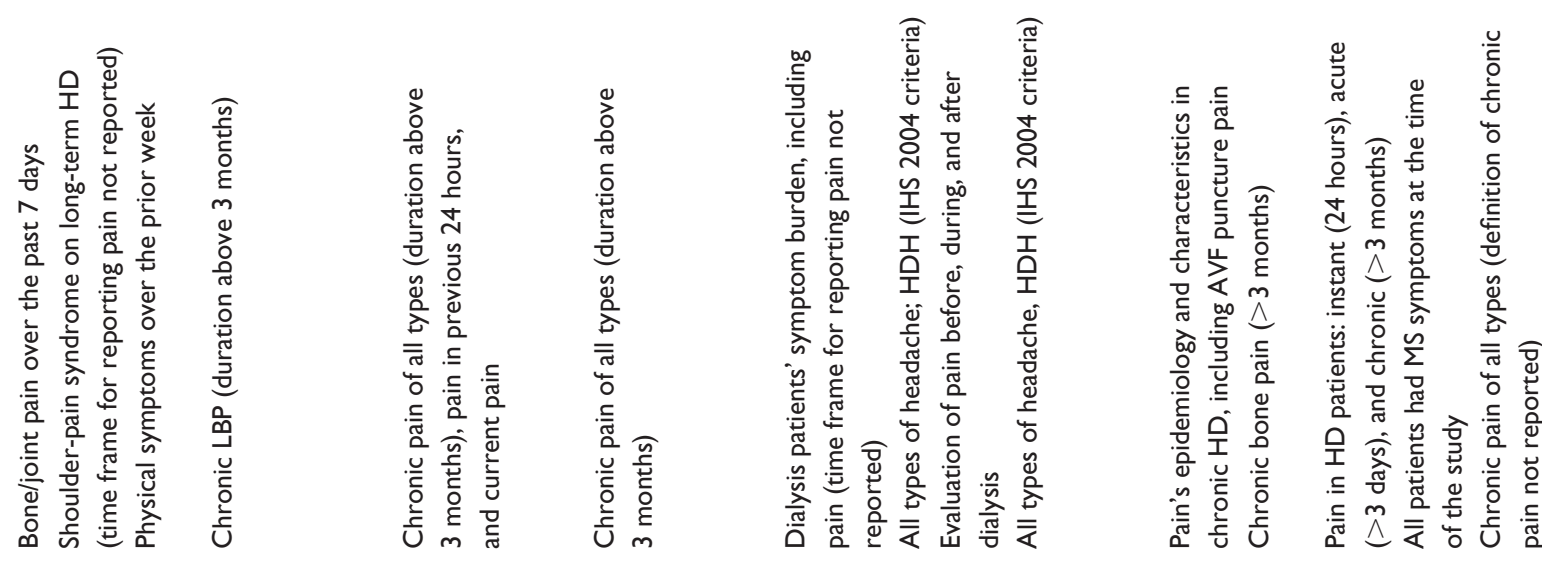

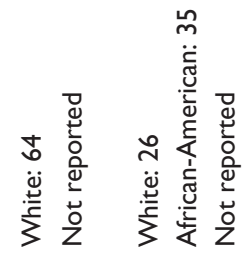

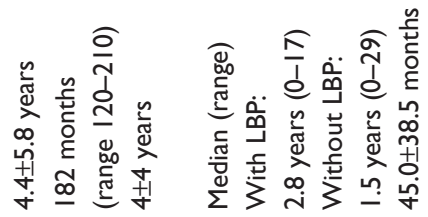

ลิก นกำ

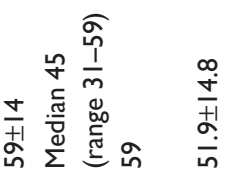

กㄴำ ํำ

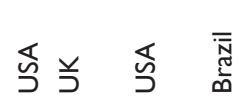

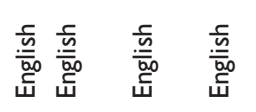
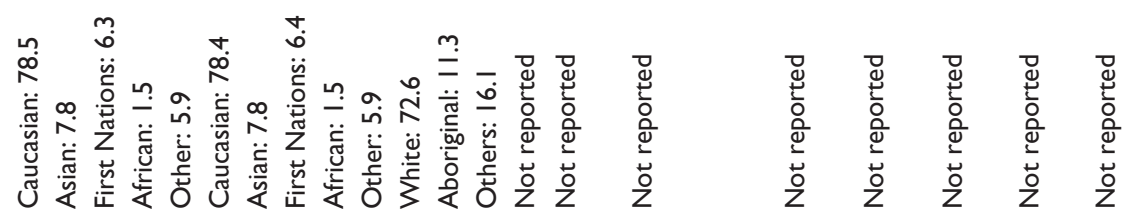

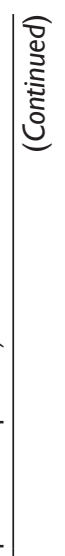



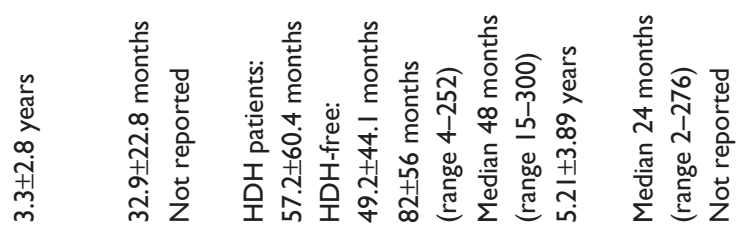



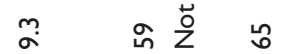

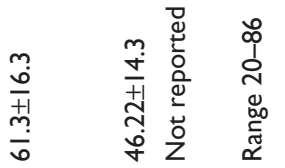

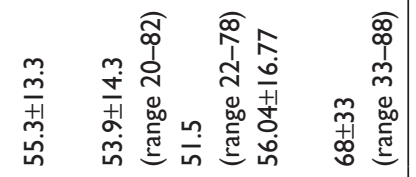

ํํำ

$\bar{\sigma} \quad$ 늠

능 응

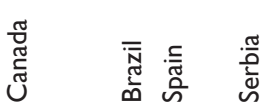

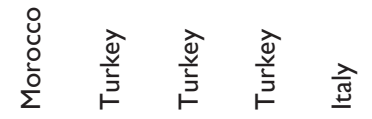

莺

$\underset{\frac{5}{\frac{5}{b 0}}}{\frac{5}{4}}$

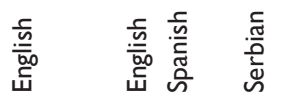

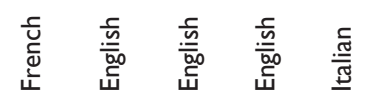

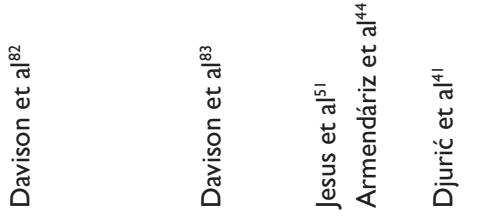




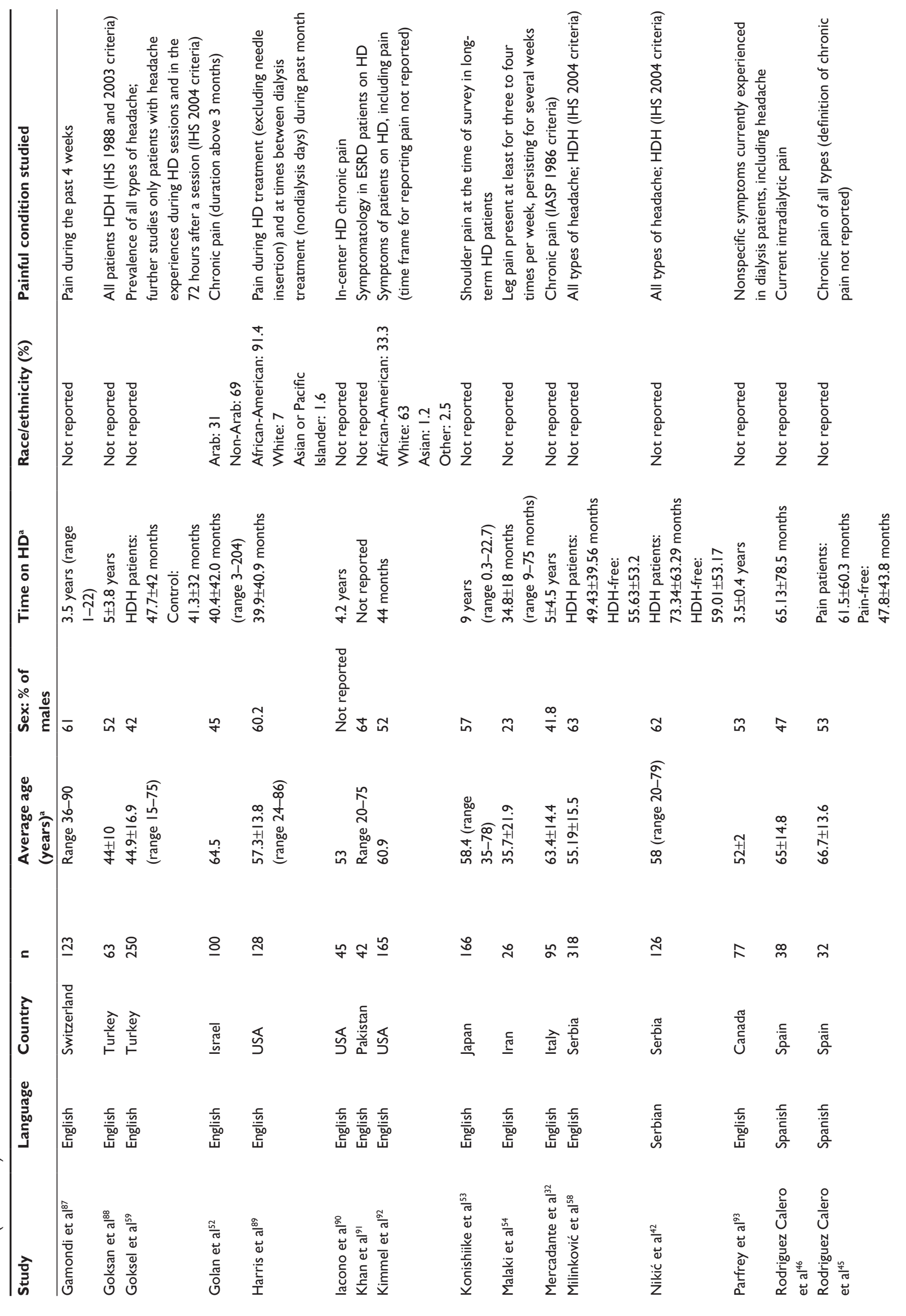




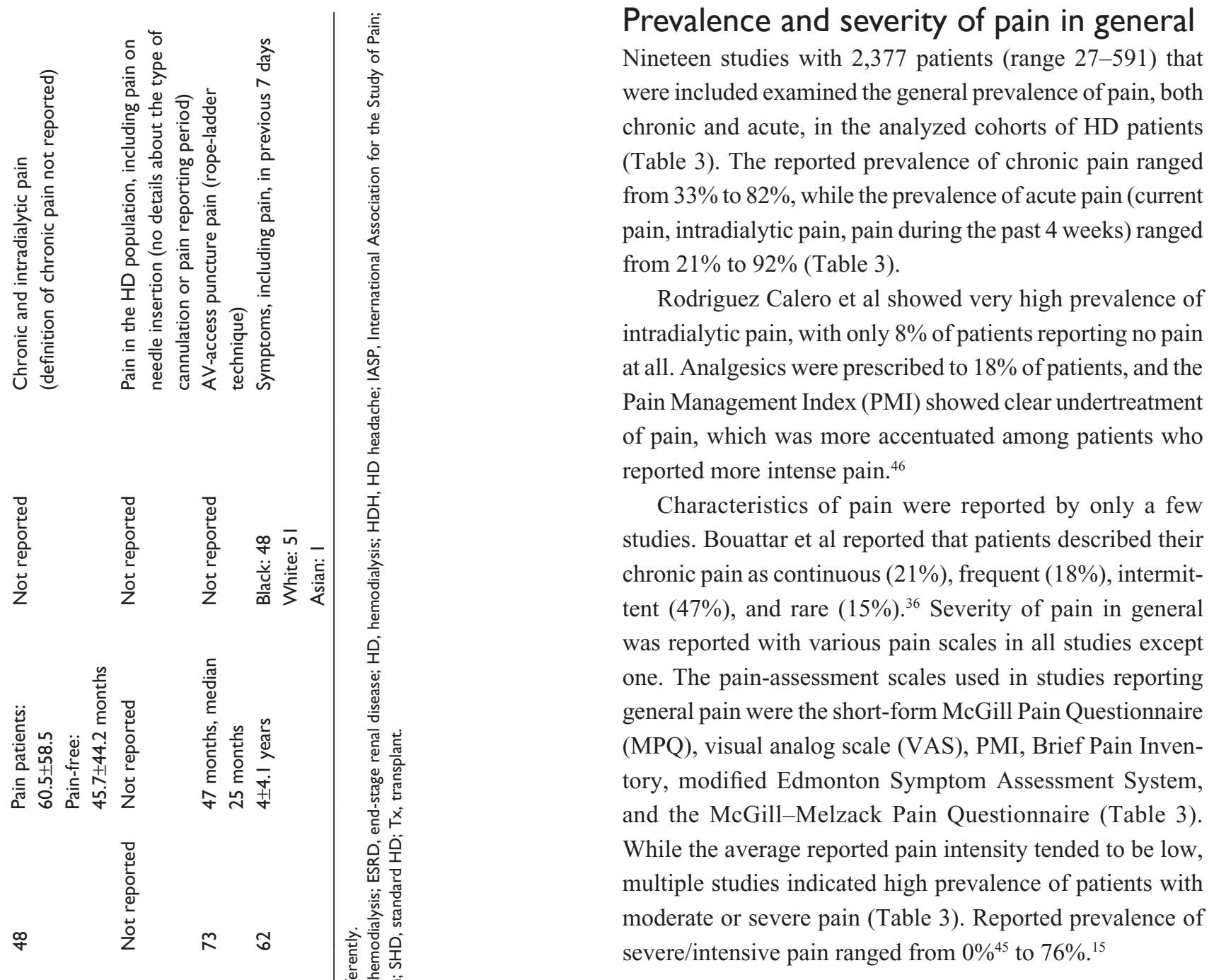

\section{Prevalence and severity of AV-access pain}

In the included studies, pain related to AV access was described in various terms, relating not only to AV fistula (AVF), which is why the broader term "AV access" is used herein to describe pain reported in these studies.

Ten studies with a total of 1,028 patients (range 25-449) analyzed prevalence and/or severity of pain related to AV access (Table 4). If available, type of AV access was extracted (Table 4). Only two studies provided details about AV access. Aitken et $\mathrm{a}^{55}$ indicated that there was a trend toward more severe pain with rope-ladder cannulation (27.7\%) compared to buttonhole cannulation (18.2\%); however, this difference did not reach statistical significance $(P=0.09)$. In Vergne et al, some patients had rope-ladder cannulation of AVF, but some also had a graft. ${ }^{35}$

The majority of studies were observational, with two interventional studies reporting baseline pain intensity. ${ }^{35,56}$ The prevalence of acute and chronic pain or both was studied, ranging from $12 \%^{57}$ to $80.2 \%{ }^{52}$ (Table 4). Severity of pain was not always reported. Different pain-assessment scales 


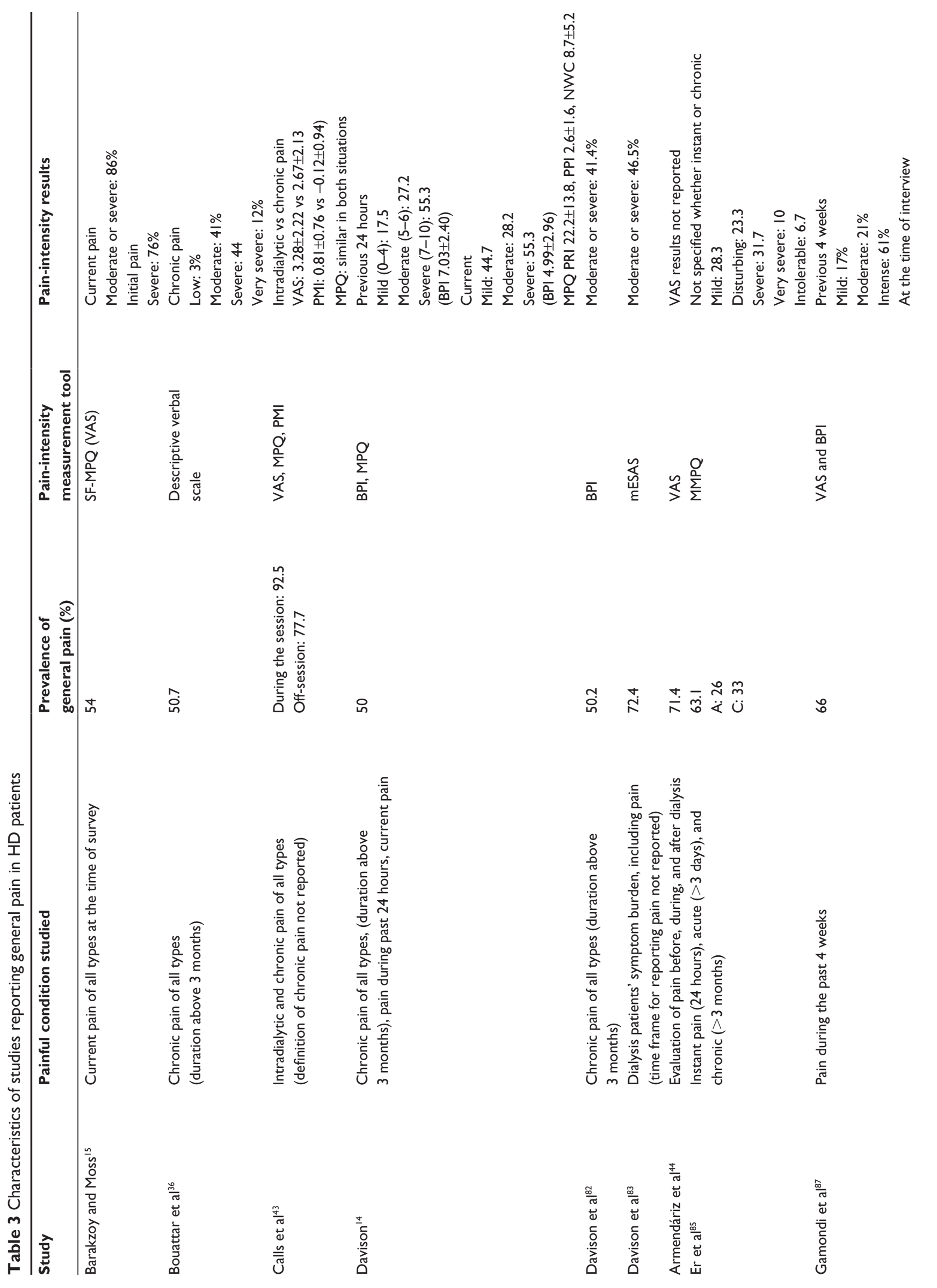




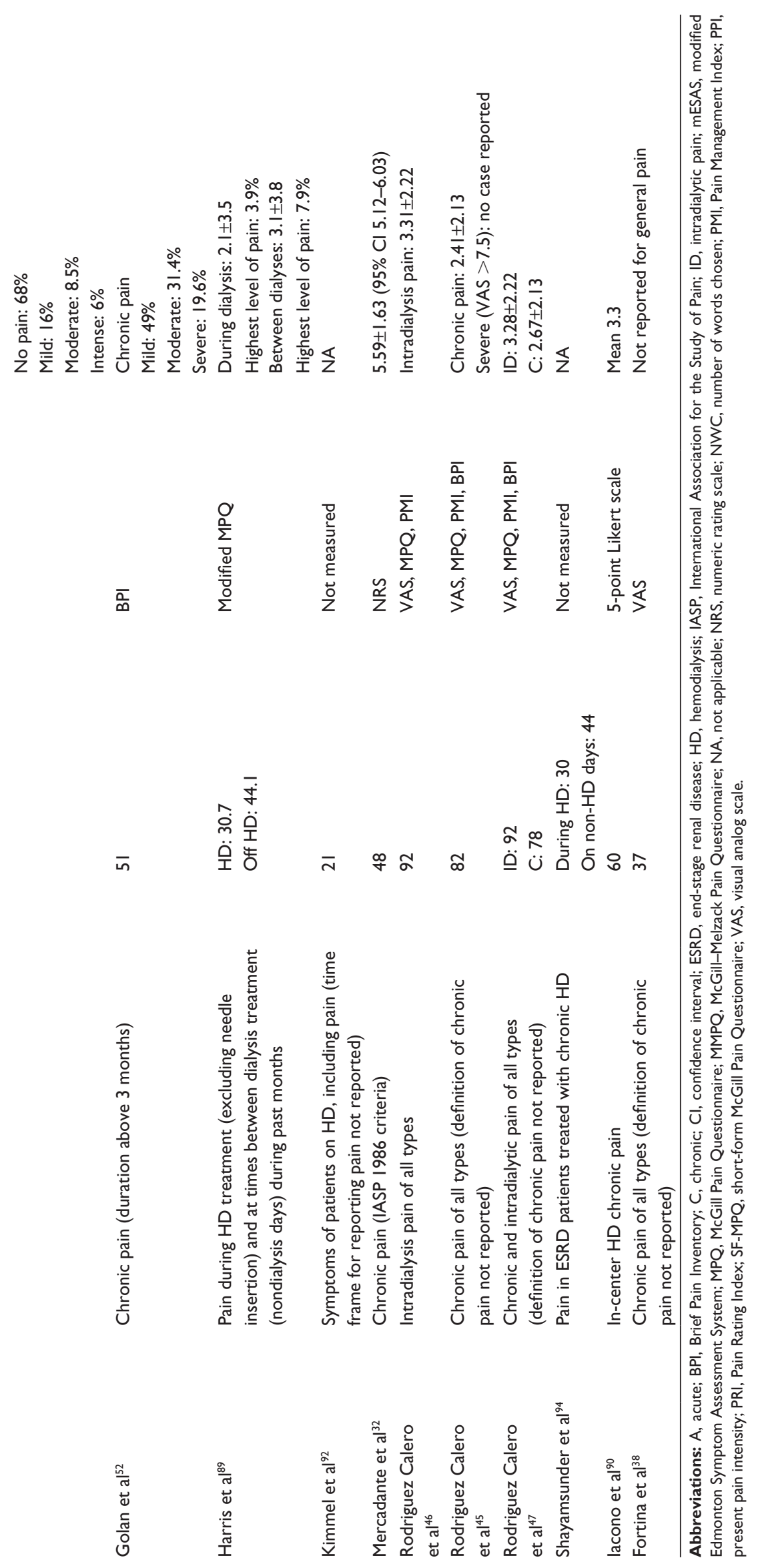




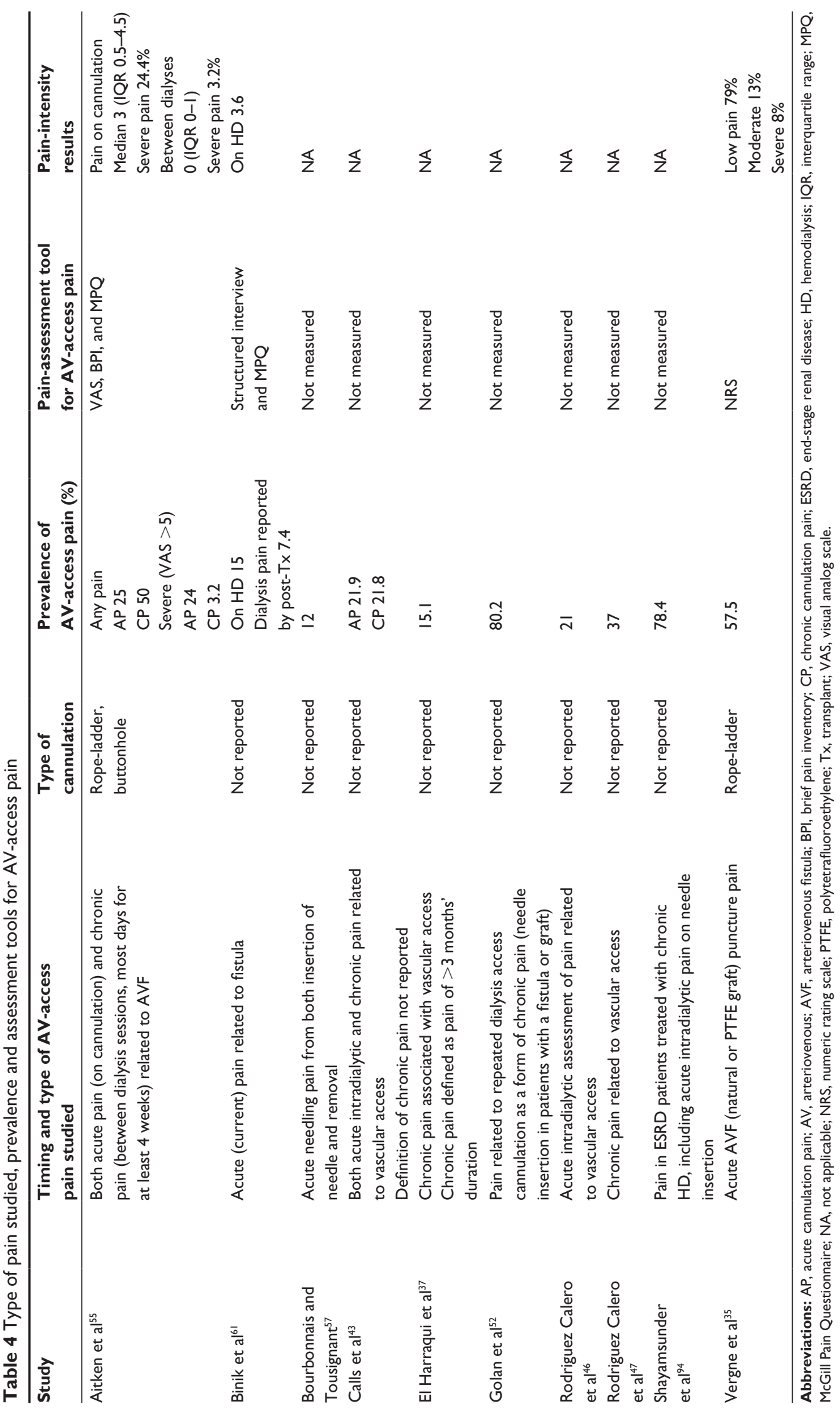


were used, including the MPQ, VAS, Brief Pain Inventory, PMI, and numeric rating scale.

\section{Prevalence and severity of headache}

A total of 24 studies with 3,444 patients (range 24-519) analyzed prevalence and/or severity of headache in HD patients. Some studies looked for headache as part of the overall symptom burden in HD patients; a subset of studies analyzed different types of headache in HD patients, while some analyzed specifically HD headache (HDH) (Table 5). Two studies were interventional, ${ }^{33,34}$ and prevalence of headache before the intervention was reported for those studies. The other studies were observational.

Reported prevalence rates of headache in HD patients varied considerably. For presentation of these results, it is important to emphasize that some studies reported prevalence of all headaches, while others reported specifically prevalence of HDH according to International Headache Society (IHS) diagnostic criteria. Some studies reported both. The reported prevalence of all kinds of headaches ranged from $11.8 \%{ }^{36}$ to $76.1 \% .{ }^{51}$ The reported prevalence of $\mathrm{HDH}$, diagnosed according to the 1988 or 2004 IHS criteria, ranged from $6.6 \%{ }^{58}$ to $68 \%{ }^{39}$ (Table 5).

Severity of headache was assessed with various scales, including descriptive scales, the MPQ, and the VAS. Different severity of headache was observed in the included studies, indicating that headache pain can be very debilitating. Analyzing types of headache, Goksel et al reported average pain intensity on the VAS as $6.06 \pm 2.4 .{ }^{59}$ The prevalence of severe pain ranged from $36 \%^{51}$ to $88 \%^{41}$ (Table 5).

\section{Prevalence of limb pain}

Six studies with 422 patients (range 26-205) reported the prevalence of lower- and/or upper-limb pain without analyzing causes of that pain. Studied pain was chronic, acute, or both (Table 6). The reported prevalence of chronic lowerleg pain was very similar in the three studies examining this type of pain, while the prevalence of lower-leg pain lasting several weeks was $42 \%$ and current intradialytic pain reported by $34 \%$ of patients in the three studies that examined it. Chronic upper-limb pain prevalence was more heterogeneous (Table 6). A sixth study reported the prevalence of chronic peripheral neuropathy as $13 \%$ without specifying the affected body part. ${ }^{14}$ None of the studies reported pain severity of limb pain.

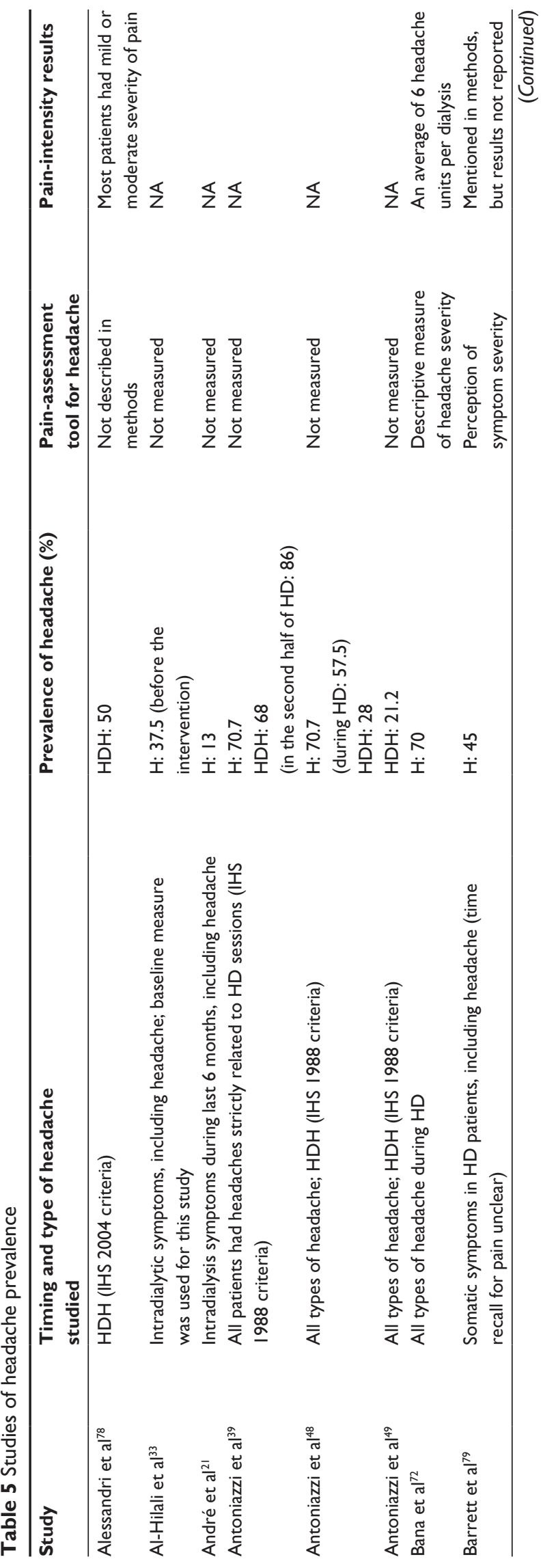




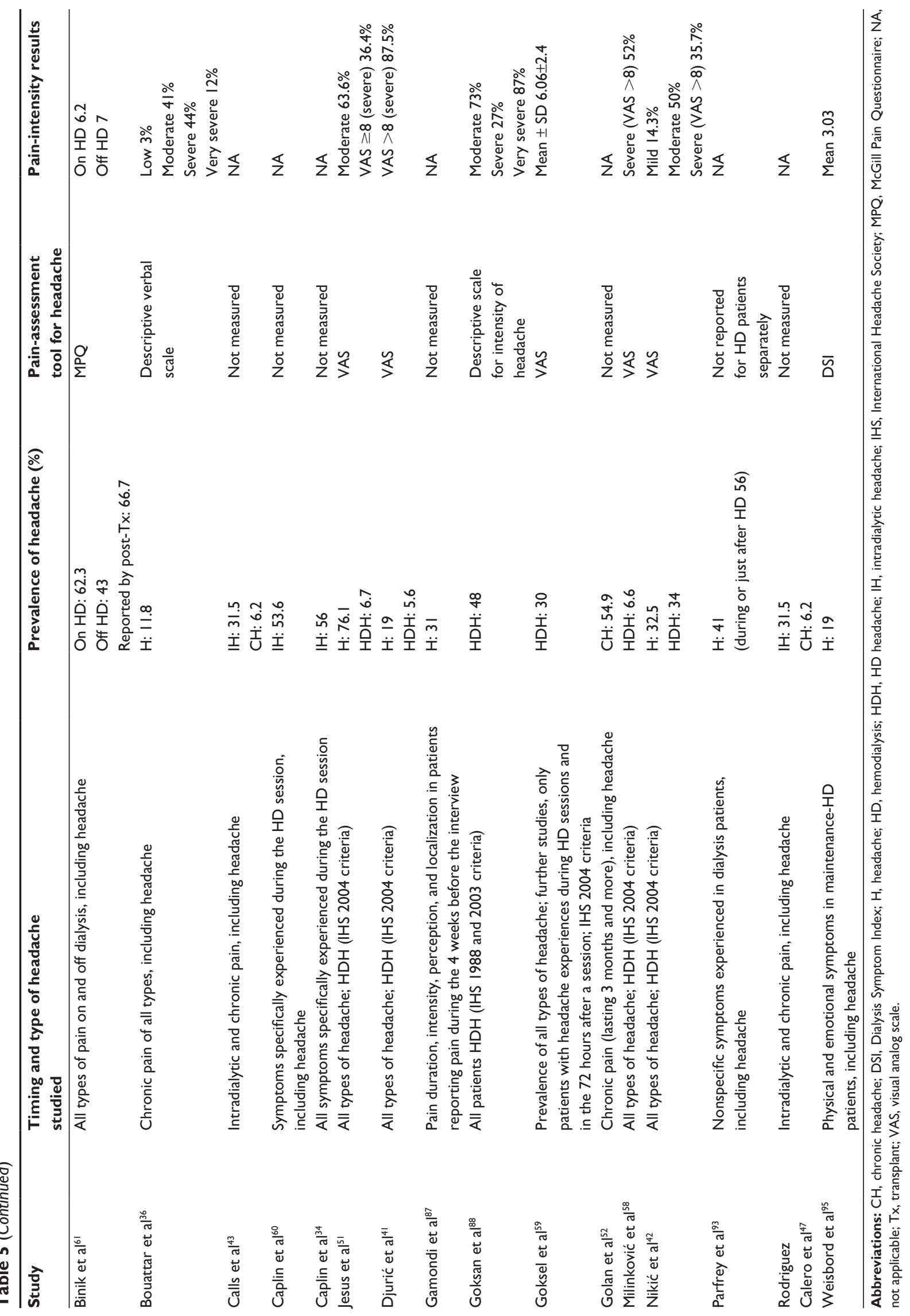


Table 6 Prevalence of limb pain

\begin{tabular}{|c|c|c|}
\hline Study & Painful condition studied & Prevalence of limb pain (\%) \\
\hline \multirow[t]{2}{*}{ Bouattar et $\mathrm{a}^{36}$} & Chronic pain of all types (duration above 3 months), & UL 74 \\
\hline & including upper- and lower-limb pain & LL 62 \\
\hline \multirow[t]{2}{*}{ Calls et al ${ }^{43}$} & Intradialytic and chronic pain (definition of chronic pain not & LL: ID 34, C 63 \\
\hline & reported), including upper- and lower-limb pain & UL: ID II, C I9 \\
\hline Davison $^{14}$ & Chronic pain (duration above 3 months), including painful PN & $\mathrm{PN} 13$ \\
\hline Malaki et $\mathrm{a}^{54}$ & $\begin{array}{l}\text { Leg pain present at least three to four times per week, } \\
\text { persisting for several weeks }\end{array}$ & LL 42 \\
\hline Rodriguez Calero et $\mathrm{al}^{46}$ & Current intradialytic pain & LL 34 \\
\hline Rodriguez Calero et a $\left.\right|^{45}$ & $\begin{array}{l}\text { Chronic pain of all types (definition of chronic pain not } \\
\text { reported), including lower-limb pain }\end{array}$ & LL 63 \\
\hline \multirow[t]{2}{*}{ Rodriguez Calero et al ${ }^{47}$} & Intradialytic and chronic pain (definition of chronic pain not & UL: ID I0.5, C I8.7 \\
\hline & reported), including upper- and lower-limb pain & LL: ID 34.2, C 62.5 \\
\hline
\end{tabular}

Abbreviations: C, chronic; ID, intradialytic; LL, lower limb; PN, peripheral neuropathy; UL, upper limb.

\section{Prevalence and severity of musculoskeletal pain}

A total of 21 studies with 2,778 patients (range 15-519) reported the prevalence of musculoskeletal pain in HD patients (Table 7). The studies reported different types of pain, ranging from carpal tunnel syndrome to muscle cramps. Data on pain severity for musculoskeletal pain indicated that such pain can be considerable (Table 7).

\section{Prevalence of chest pain}

Six studies with 747 patients (range 27-508) reported the prevalence of chest pain in HD patients. ${ }^{36,43,46,47,60,61}$ Two studies reported the prevalence of intradialytic pain as exactly $2.6 \%,{ }^{43,46}$ while the third found chest pain during HD sessions to be $25 \%{ }^{60}$ Chronic chest pain was reported to be $5.9 \%{ }^{36}$ and $9.3 \% .{ }^{43}$ Binik et al reported chest pain both on and off dialysis in $13 \%$ of the sample. ${ }^{61}$ Only Binik et al reported pain severity using MPQ score as 6.4 on dialysis and 6.9 off dialysis. ${ }^{61}$

\section{Prevalence and severity of abdominal pain}

Six studies reported the prevalence of abdominal pain. ${ }^{36,43,46,47,52,61}$ Prevalence of intradialytic abdominal pain was reported as $16 \%$ in two studies, ${ }^{43,46}$ chronic abdominal pain as $18 \%$ in two studies ${ }^{36,52}$ and $9.3 \%$ in one study ${ }^{43}$ Binik et al reported the prevalence of abdominal pain both on and off dialysis as $17 \% .{ }^{61}$ Only one study reported the severity of abdominal pain as being 7.3 on MPQ score for on-HD abdominal pain. ${ }^{61}$

\section{Prevalence of other pain}

Several studies reported the prevalence of "other" pain, but this type of pain was rarely specified. Golan et al reported that $13 \%$ of patients had chronic pain from various other sources, such as phantom pain, steal syndrome, and nonspecific diffuse pain. ${ }^{52}$ Davison found prevalence of other combined chronic pain (including trauma, polycystic kidney disease, malignancy, and calciphylaxis) to be $18.4 \%{ }^{14}$ Claxton et al reported the prevalence of other pain over the prior week as $18 \%$, but without specifying any details about the location or causes of that pain. ${ }^{62}$ Calls et al ${ }^{43}$ and Rodriguez Calero et $\mathrm{al}^{47}$ (using the same raw data) reported the prevalence of other (polycystic kidney disease, neoplasia) pain during HD sessions as $3.7 \%$ and chronic pain as $7.4 \%$. Severity of pain listed as "other" was not reported in these studies.

\section{Prevalence of procedural pain}

Five studies reported the prevalence of poorly defined "procedural pain". ${ }^{14,43,45-47}$ Calls et al reported that $26 \%$ of patients suffered from procedural pain, including cramps, headaches, and pain related to vascular access. ${ }^{43}$ Davison reported that $6.8 \%$ of patients experienced significant pain due to recurrent symptoms related to HD that included "cramping, headaches, and access-related pain, such as pain from needling fistulas and pain in the fistula hand". This represented $14 \%$ of patients reporting a problem with pain. ${ }^{14}$ Rodriguez Calero et al reported that $25.9 \%$ patients identified the procedure itself as the cause of the pain, ${ }^{47}$ while another study showed a slightly higher prevalence (29\%). ${ }^{46}$ Finally, according to their most recent results, $38 \%$ suffered from procedure-related pain. ${ }^{45}$ Therefore, while three studies did not explain what procedural pain was, ${ }^{45-47}$ the other two explained that procedural pain can have different locations and causes, ${ }^{14,43}$ which were reported as specific types of pain in other studies included in this review. 


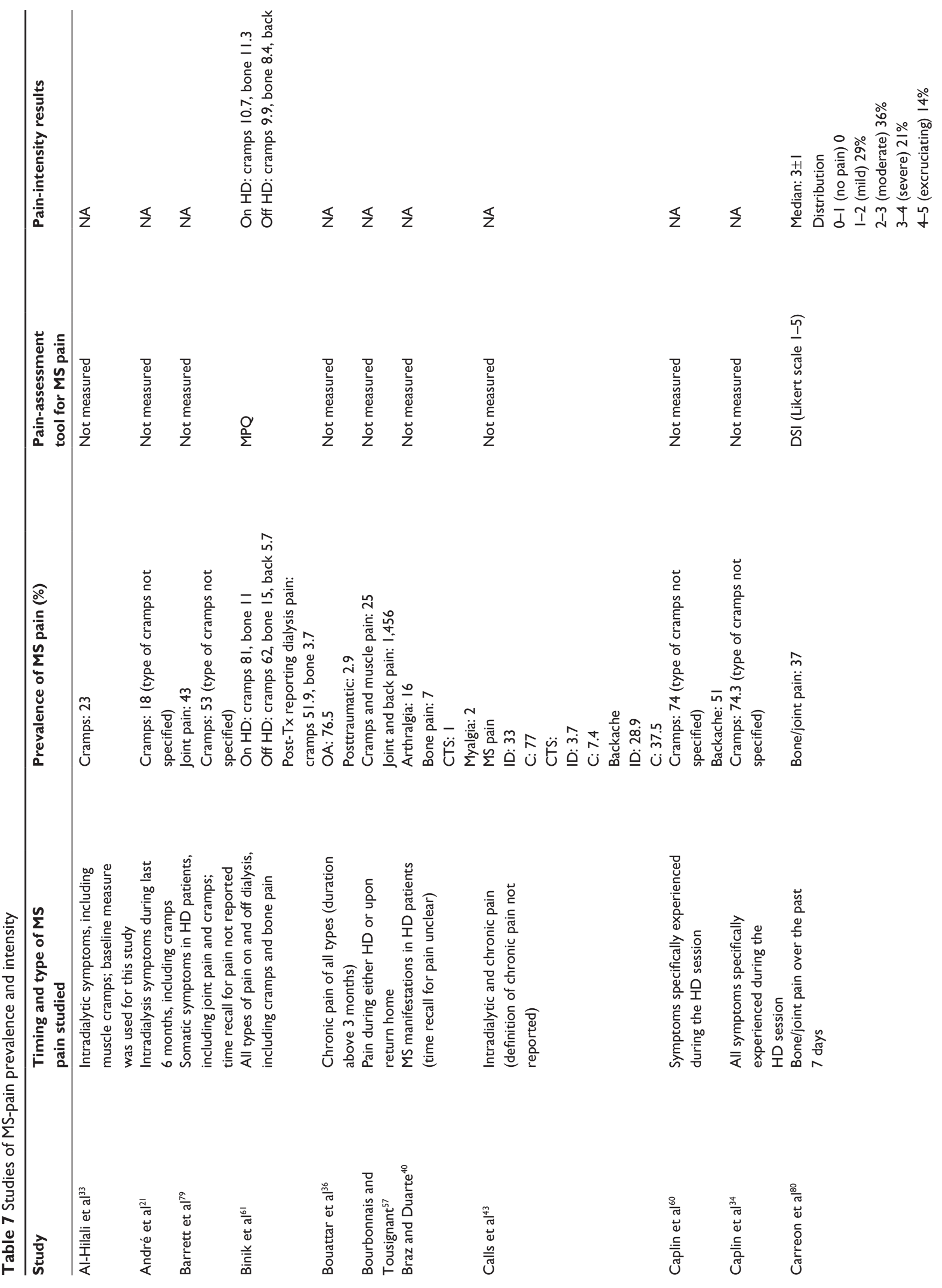




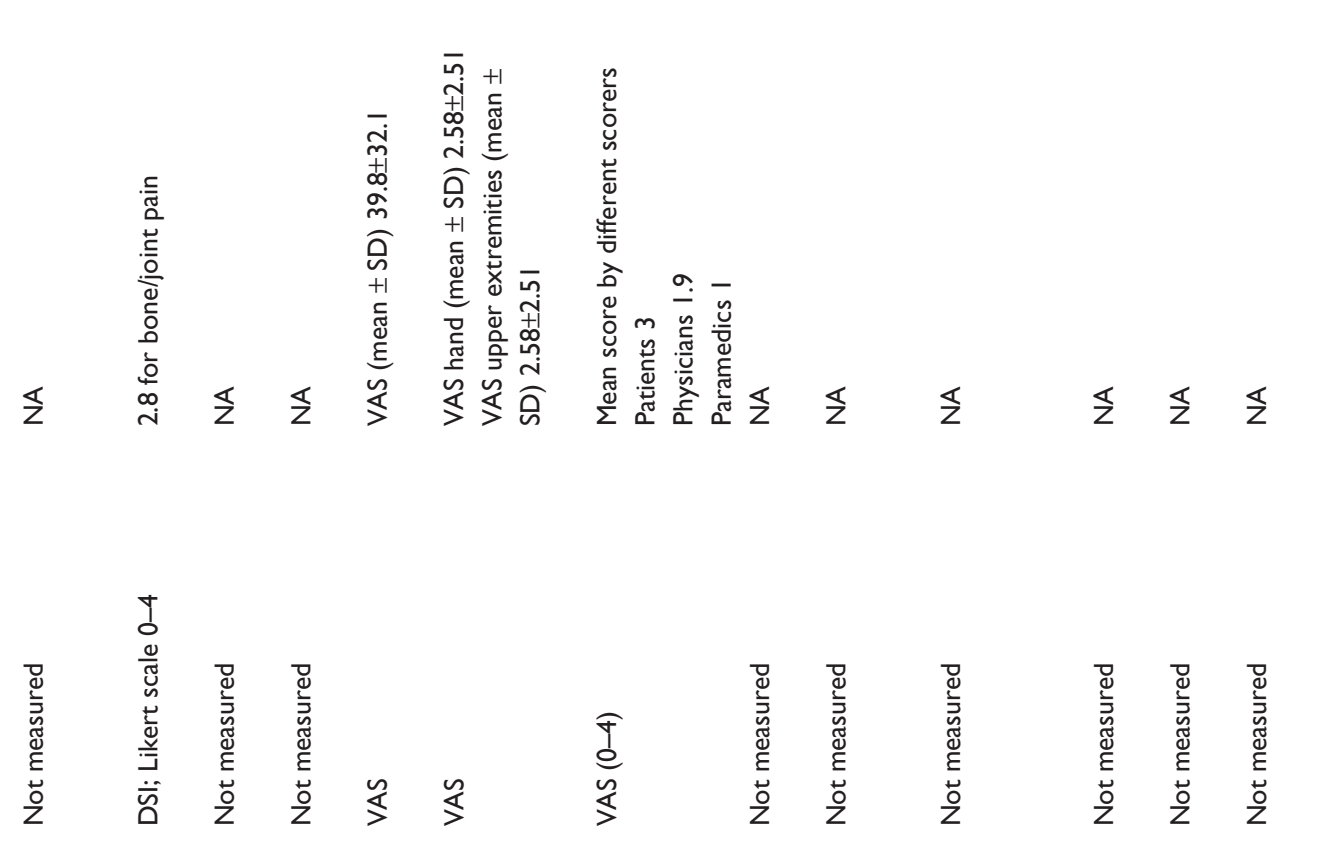

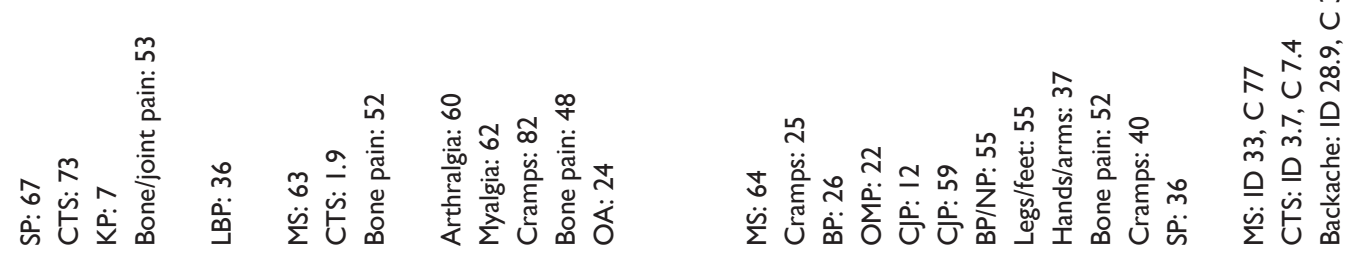
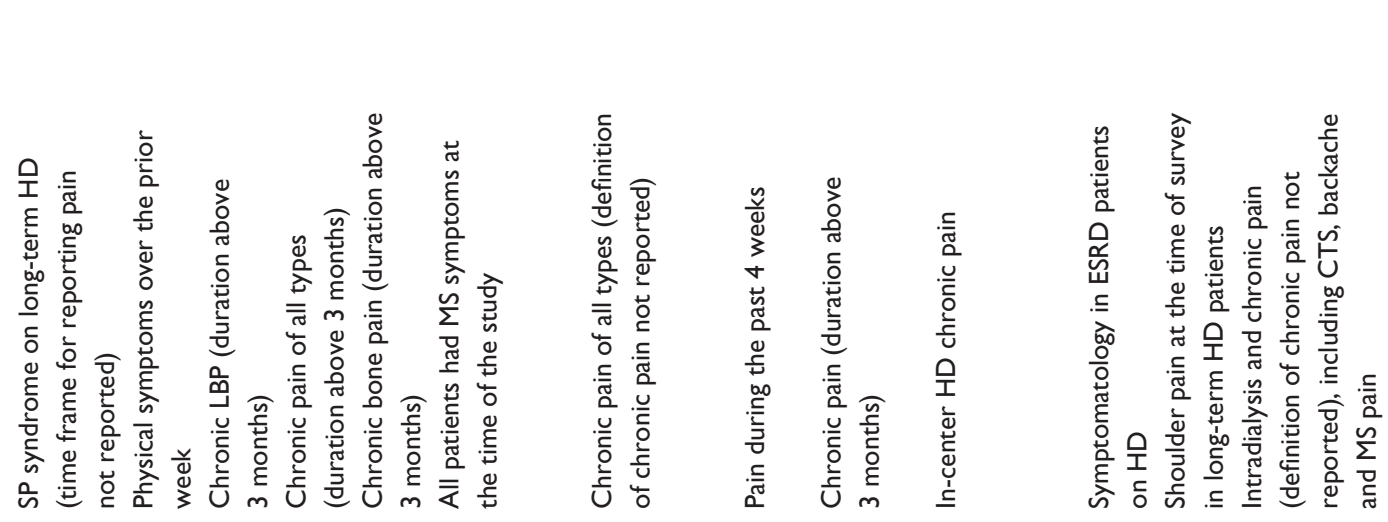

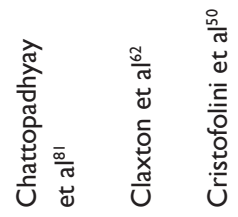

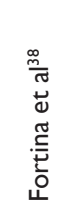

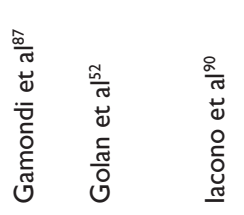
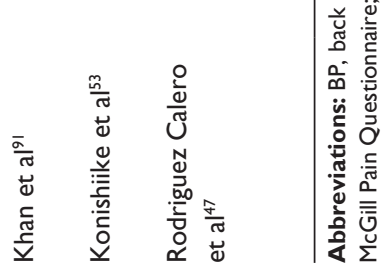


\section{Prevalence of ischemic pain}

Prevalence of ischemic pain as a cause of pain was reported in three studies. ${ }^{43,45,46}$ In a study on current dialytic pain, with a prevalence of $32 \%$ it was reported as the most prevalent cause of pain, ${ }^{46}$ while in another study on intradialytic ischemic pain its prevalence was even higher $-37 \%{ }^{43}$ Prevalence of ischemic pain as a cause of chronic pain was reported as $25 \%{ }^{45}$ and $30 \%{ }^{43}$

\section{Prevalence of neuropathic pain}

According to the literature, while a high percentage of HD patients have shown electrophysiological evidence of nerve damage, only a small proportion have been reported as suffering from neuropathic pain. ${ }^{63-65}$ Generally, it occurs more frequently in males. Only three studies reported the prevalence of neuropathic pain. ${ }^{14,15,52}$ The older the study was, the higher the prevalence shown. Davison reported a prevalence of neuropathic pain as $12.6 \% .{ }^{14}$ Three years later, Barakzoy and Moss reported it as $31 \%,{ }^{15}$ while Golan et al yielded a figure of $41.2 \% .^{52}$

\section{Quality of included studies}

The STROBE checklist indicated that 49 observational studies were generally of moderate quality: scores ranged in sum from 6 to 18, with a median of 13 points. Three interventional studies assessed using the Cochrane risk-of-bias tool had high or unclear risk of bias in six of seven domains. Conflict of interest in the included studies was reported in only eleven of 52 studies: nine acknowledged support from public governmental grants/institutions or a private foundation; one indicated support from a small educational grant, but the source of the grant was not mentioned; while one study simply indicated that there was no conflict of interest.

\section{Discussion}

The results of this systematic review offer a comprehensive view of epidemiological studies on pain in HD patients, indicating that pain can be very prevalent and severe in HD patients. Although some studies did not examine pain as a single concept, but reported specifically pain affecting certain body parts, such as headache or musculoskeletal pain, a uniform conclusion of the included studies indicates that pain is very prevalent in HD patients.

We found that the prevalence of acute and chronic pain in HD patients can be up to $82 \%$ and $92 \%$, respectively, which is consistent with previous research. A previously published systematic review of symptom prevalence in ESRD, which included 59 studies, reported a mean HD-pain prevalence of $47 \%$ (8\%-82\%). ${ }^{66}$ Identifying prevalence rates has pertinent implications for investigating the fundamental pathophysiology and developmental pathways of pain in HD. Beyond reporting prevalence of general pain, the prevalence of various types of pain in HD patients was also reviewed in this study. Most of the studies reported the prevalence of pain related to AV access, headache, and musculoskeletal pain.

Pain related to AV access is a particular type of pain that can be expected in all HD patients. Vascular access is required to permit HD. AVF is the most effective and efficient method of achieving vascular access. ${ }^{55}$ However, if HD is performed three times per week via AVF, this will repeatedly expose patients to the stress and pain of approximately 320 needle punctures/year. It is often necessary to make more than one attempt at cannulation to maintain an adequate blood flow. ${ }^{25}$ It is necessary to use large needles to achieve the required rate of flow for dialysis, which can often lead to bruising and pain, especially in patients with new fistulae. ${ }^{55}$

It has been suggested in the literature that AVF cannulation is an easy and painless procedure. ${ }^{28}$ However, it has been shown that repeated insertion of the AVF needles can cause considerable pain, both on and between dialysis sessions, with subsequent fear and anxiety. ${ }^{25}$ Patients consider pain during needle insertion the most common problem regarding dialysis vascular access. ${ }^{25,67} \mathrm{AVF}$-cannulation pain may adversely impact quality of life, and pain is cited as the primary reason for patients failing to tolerate dialysis via AVF. ${ }^{68}$ Even though severe pain leading to regular avoidance of dialysis or abandonment of AVF is rare, over $10 \%$ of patients have experienced pain severe enough to require early cessation of $\mathrm{HD}$ at least once. ${ }^{55}$

There have been a number of published systematic reviews ${ }^{69-71}$ on the impact of the different puncturing technique on the incidence of AVF-cannulation pain, all with equivocal results, showing various limitations, such as incomplete literature search ${ }^{69}$ or even overall poor quality and substantial heterogeneity among studies that precluded pooling of outcomes. ${ }^{70}$ Pain arising from AVF access was common and often multimodal in nature, frequently leading to avoidance or shortening of dialysis sessions and even abandonment of otherwise well-functioning AVF. Furthermore, pain is often a sign of underlying anatomical problems with AVF, and should always be investigated in the first instance. ${ }^{55}$

A considerable number of studies in this systematic review analyzed the prevalence and/or severity of headache. Bana et al first described headache during HD in 1972, and reported its prevalence as $70 \% .{ }^{72}$ Before 1988 , the taxonomy 
of headache was not uniform, and diagnostic criteria were rarely based on operational rules. In 1988, the IHS instituted a classification system that has become the standard for headache diagnosis and clinical research. The classification was endorsed by all the national headache societies represented in the IHS and also by the World Federation of Neurology. ${ }^{73}$ The 1988 IHS criteria for headache related to HD consider that the headaches must begin during HD and terminate within 24 hours. However, it has been noted that some headaches cannot be classified. ${ }^{48}$ The IHS revised the criteria for $\mathrm{HDH}$ in 2004, and described this condition as a headache that starts during an HD session and resolves within 72 hours after the session. ${ }^{74}$ Our systematic review has shown the prevalence of headache, and particularly $\mathrm{HDH}$, to be very high and among the most common problems in the HD population.

With regard to musculoskeletal pain, Braz and Duarte indicated that they excluded patients with previously confirmed rheumatologic disease or who said they had any osteoarticular manifestation before the HD treatment (episode of arthritis of unknown etiology, bursopathy, and diffuse bone pain, among others, not properly investigated or undiagnosed) to prevent these as potential confounding factors. ${ }^{40}$ Such a statement was not present in other studies reporting general, limb, or musculoskeletal pain. Therefore, it is highly likely that high prevalence of limb and musculoskeletal pain in HD patients indicates comorbidities, and not such pain related to $\mathrm{HD}$.

One of the strengths of this study is the inclusion of literature published in languages other than English and gray literature. In this way, we were able to locate multiple studies that were conducted outside Europe and North America. These studies indicated that pain is a considerable burden in developing countries as well.

Although this paper provides valuable data on the prevalence and severity of pain in HD patients, there were numerous limitations in the available evidence from primary studies. Data included in this systematic review indicate gaps that we still need to overcome in future literature on pain in HD patients. First, very few studies on the prevalence and severity of pain in HD patients were conducted in developing countries. Studies from those settings would be welcome for informing practice and research needs. Second, future studies need to pay particular attention to reporting, specifically for which period a patient is reporting pain. Several included studies did not report recall time for pain. Chronic pain was mostly defined as pain duration $\geq 3$ months, but some studies did not define what they considered chronic pain, while some indicated that they measured chronic pain as pain lasting at least 4 weeks. ${ }^{55}$ Future studies should clearly indicate what they consider to be chronic pain and when exactly the pain was measured, ie, what the recall period expected of patients was (ie, current pain, pain in the last week, pain lasting $\geq 3$ months).

Third, sample sizes need to be bigger. Half of the studies presented herein were small, with fewer than 100 patients included. The estimates of pain were sometimes based on median prevalence rates that may have been affected by the small sample size used, and should thus be interpreted with caution. Future studies should include a sufficient number of patients to gain a more representative sample. Fourth, validated pain-assessment tools should be used. The studies included in this review used various scales for pain assessment, which hinders comparability of pain intensity. While some studies used measures of pain intensity/severity to report average pain intensity, others reported the prevalence of different pain intensities in the analyzed sample. Future studies should all use the VAS for pain reporting, together with other pain-assessment scales. Additionally, studies should also report average pain, as well as percentage of patients experiencing different pain intensities. Furthermore, some of the included studies did not provide clear definitions of certain modalities of pain, such as cramps, making it difficult to judge whether these were indeed musculoskeletal cramps that are typical for HD patients. ${ }^{75,76}$ Finally, the quality of the included studies was low to moderate. The authors of future studies should consult checklists for conducting and reporting trials, in order to improve the quality of available evidence.

The role of systematic reviews is to provide reliable actionable evidence, and also to point out where evidence is missing or when there are gaps in our research knowledge. ${ }^{77}$ This systematic review provided a comprehensive overview of our current knowledge of the prevalence and severity of pain in HD patients, with actionable guidance for future studies on this topic. Based on the available evidence, prevalence and severity of pain varied widely between studies. It is thus necessary to explore factors associated with pain in HD patients to gain insight into the reasons behind such heterogeneity in pain prevalence and severity.

\section{Conclusion}

The findings of this systematic review indicated a high prevalence of pain in HD patients, and thus pain in this population should be recognized as a considerable health concern. This review should encourage the nephrology community to promote pain management in HD patients as a clinical and research priority for improving quality of life 
and pain-related disability. However, there are considerable gaps in the literature that future studies should address when devising a study protocol.

\section{Acknowledgments}

We are very grateful to Ms Ana Utrobicic for helping us to retrieve full texts of the manuscripts. Thanks to Ms Dalibora Behmen for professional English-language editing.

\section{Disclosure}

The authors report no conflicts of interest in this work.

\section{References}

1. Hoerger TJ, Simpson SA, Yarnoff BO, et al. The future burden of CKD in the United States: a simulation model for the CDC CKD Initiative. Am J Kidney Dis. 2015;65(3):403-411.

2. Kovesdy CP, Mehrotra R, Kalantar-Zadeh K. Battleground: chronic kidney disorders mineral and bone disease - calcium obsession, vitamin $\mathrm{D}$, and binder confusion. Clin J Am Soc Nephrol. 2008;3(1):168-173.

3. Schiffrin EL, Lipman ML, Mann JF. Chronic kidney disease: effects on the cardiovascular system. Circulation. 2007;116(1):85-97.

4. Robinson BE. Epidemiology of chronic kidney disease and anemia. $J$ Am Med Dir Assoc. 2006; 7(9 Suppl):S3-S6; quiz S17-S21.

5. Hsu HJ, Yen CH, Hsu KH, et al. Factors associated with chronic musculoskeletal pain in patients with chronic kidney disease. BMC Nephrol. 2014; $15: 6$

6. Tong A, Wong G, McTaggart S, et al. Quality of life of young adults and adolescents with chronic kidney disease. J Pediatr. 2013;163(4): 1179-1185.e5.

7. Kul M, Çengel-Kültür SE, Şenses-Dinç G, Bilginer Y, Uluç S, Baykan H. Quality of life in children and adolescents with chronic kidney disease: a comparative study between different disease stages and treatment modalities. Turk J Pediatr. 2013;55(5):493-499.

8. Feng L, Yap KB, Ng TP. Depressive symptoms in older adults with chronic kidney disease: mortality, quality of life outcomes, and correlates. Am J Geriatr Psychiatry. 2013;21(6):570-579.

9. Lapane KL, Quilliam BJ, Benson C, Chow W, Kim MS. Impact of noncancer pain on health-related quality of life. Pain Pract. 2015;15(4): 333-342.

10. Hsu CY, Vittinghoff E, Lin F, Shlipak MG. The incidence of end-stage renal disease is increasing faster than the prevalence of chronic renal insufficiency. Ann Intern Med. 2004;141(2):95-101.

11. Hallan SI, Coresh J, Astor BC, et al. International comparison of the relationship of chronic kidney disease prevalence and ESRD risk. $J \mathrm{Am}$ Soc Nephrol. 2006;17(8):2275-2284.

12. Eriksen BO, Ingebretsen OC. The progression of chronic kidney disease: a 10-year population-based study of the effects of gender and age. Kidney Int. 2006;69(2):375-382.

13. Levey AS, de Jong PE, Coresh J, et al. The definition, classification, and prognosis of chronic kidney disease: a KDIGO Controversies Conference report. Kidney Int. 2011;80(1):17-28.

14. Davison SN. Pain in hemodialysis patients: prevalence, cause, severity, and management. Am J Kidney Dis. 2003;42(6):1239-1247.

15. Barakzoy AS, Moss AH. Efficacy of the World Health Organization analgesic ladder to treat pain in end-stage renal disease. $J \mathrm{Am} \mathrm{Soc}$ Nephrol. 2006;17(11):3198-3203.

16. Santoro D, Satta E, Messina S, Costantino G, Savica V, Bellinghieri G. Pain in end-stage renal disease: a frequent and neglected clinical problem. Clin Nephrol. 2013;79 Suppl 1:S2-S11.

17. Centre for Reviews and Dissemination. Systematic Reviews: CRD's Guidance for Undertaking Systematic Reviews in Health Care. York, UK: CRD; 2009.
18. Stroup DF, Berlin JA, Morton SC, et al. Meta-analysis of observational studies in epidemiology: a proposal for reporting. JAMA. 2000;283(15): 2008-2012.

19. von Elm E, Altman DG, Egger M, Pocock SJ, Gøtzsche PC, Vandenbroucke JP. The Strengthening the Reporting of Observational Studies in Epidemiology (STROBE) statement: guidelines for reporting observational studies. Int J Surg. 2014;12(12):1495-1499.

20. Higgins JP, Altman DG, Gøtzsche PC, et al. The Cochrane Collaboration's tool for assessing risk of bias in randomised trials. BMJ. 2011;343:d5928.

21. André MB, Rembold SM, Pereira CM, Lugon JR. Prospective evaluation of an in-center daily hemodialysis program: results of two years of treatment. Am J Nephrol. 2002;22(5-6):473-479.

22. Borgel F, Benhamou PY, Zmirou D, Balducci F, Halimi S, Cordonnier D. Assessment of handicap in chronic dialysis diabetic patients (Uremidiab section study). Scand J Rehabil Med. 1992;24(4):203-208.

23. Devins GM, Armstrong SJ, Mandin H, et al. Recurrent pain, illness intrusiveness, and quality of life in end-stage renal disease. Pain. 1990;42(3): 279-285.

24. Celik G, Ozbek O, Yilmaz M, Duman I, Ozbek S, Apiliogullari S. Vapocoolant spray vs lidocaine/prilocaine cream for reducing the pain of venipuncture in hemodialysis patients: a randomized, placebocontrolled, crossover study. Int J Med Sci. 2011;8(7):623-627.

25. Figueiredo AE, Viegas A, Monteiro M, Poli-de-Figueiredo CE. Research into pain perception with arteriovenous fistula (AVF) cannulation. $J$ Ren Care. 2008;34(4):169-172.

26. Andersen C, Danielson K, Ladefoged J. EMLA cream for pain prevention in hemodialysis patients. Dial Transplant. 1989;18(12):684-685.

27. Asgari MR, Motlagh NH, Soleimani M, Ghorbani R. Effect of lidocaine spray on the pain intensity during insertion of vascular needles in hemodialysis patients. Faslnamahi Kumish. 2012;14(3):271-279.

28. Crespo R, Rivero MF, Contreras MD, Guisado C. Influence of bevel position of the needle on puncture pain in haemodialysis. EDTNA ERCA J. 1994;20(4):21-23.

29. Ludwig K, Ruder H, Wendt MA, Richter R. Pain reduction in children and adolescents on hemodialysis with local anesthetic cream. Monatsschr Kinderheilkd. 1997;145(1):60-62.

30. McPhail S. Hemodialysis needles can be pain free: use of a topical anaesthetic cream. $J$ CANNT. 1992;2(4):19-20.

31. Peiffer-Labauge A, Marcelli C, Mourad G, et al. [Painful leg syndrome in hemodialyzed patients for chronic renal insufficiency with recent kidney transplantation] Syndrome douloureux des membres inférieurs chez l'insuffisant rénal chronique hémodialyse récemment transplanté. Rev Rhum Mal Osteoartic. 1991;58(3):187-191. French.

32. Mercadante S, Ferrantelli A, Tortorici C, et al. Incidence of chronic pain in patients with end-stage renal disease on dialysis. J Pain Symptom Manage. 2005;30(4):302-304.

33. Al-Hilali N, Al-Humoud HM, Ninan VT, Nampoory MR, Ali JH, Johny KV. Profiled hemodialysis reduces intradialytic symptoms. Transplant Proc. 2004;36(6):1827-1828.

34. Caplin B, Alston H, Davenport A. Does online haemodiafiltration reduce intra-dialytic patient symptoms? Nephron Clin Pract. 2014; 124(3-4):184-190.

35. Vergne H, Darnis MC, Ostertag A, Poux JM. Douleur à la ponction de la fistule artério-veineuse en hémodialyse. 2002. Available from: http:// cnrd.fr/IMG/pdf/VERGNE.pdf. Accessed April 27, 2016.

36. Bouattar T, Skalli Z, Rhou H, et al. [The evaluation and analysis of chronic pain in chronic hemodialysis patients] Évaluation et analyse de la douleur chez les hémodialysés chroniques. Nephrol Ther. 2009; 5(7):637-641. French.

37. El Harraqui R, Abda N, Bentata Y, Haddiya I. [Evaluation and analysis of pain in chronic hemodialysis] Évaluation et analyse de la douleur en hémodialysé chronique. Nephrol Ther. 2014;10(7):500-506. French.

38. Fortina F, Agliata S, Ragazzoni E, et al. [Chronic pain during dialysis: pharmacological therapy and its costs] Il dolore chronico in dialisi. Minerva Urol Nefrol. 1999;51(2):85-87. Italian. 
39. Antoniazzi AL, Bigal ME, Bordini CA, Speciali JG. [Headache and hemodialysis: evaluation of the possible triggering factors and of the treatment] Cefaléia relacionada à hemodiálise: análise dos possíveis fatores desencadeantes e do tratamento empregado. Arq Neuropsiquiatr. 2002;60(3A):614-618. Portuguese.

40. Braz AD, Duarte AL. Musculoskeletal manifestations in hemodialysis patients. Rev Bras Reumatol. 2003;43(4):223-231.

41. Djurić M, Zidverc-Trajković J, Sternić N, et al. [Hemodialysis-related headaches] Hemodijalizne glavobolje. Vojnosanit Pregl. 2007;64(5): 319-323. Serbian.

42. Nikić PM, Zidverc-Trajković J, Andrić BR, Djurić M, Stojimirović BB. [Headache associated with haemodialysis] Glavobolja kod bolesnika na hemodijalizi. Srp Arh Celok Lek. 2008;136(7-8): 343-349. Serbian.

43. Calls J, Rodríguez Calero M, Hernández Sánchez D, et al. [An evaluation of pain in haemodialysis patients using different validated measurement scales] Evaluación del dolor en hemodiálisis mediante diversas escalas de medición validadas. Nefrologia. 2009;29(3):236-243. Spanish.

44. Armendáriz MP, Terceño AM, García ME, Blázquez SF. Evaluation of pain in patients undergoing hemodialysis. Rev Soc Esp Enferm Nefrol. 2010;13(4):264-266

45. Rodriguez Calero MA, Sánchez DH, Navarro JG, Amer FJ, Ginesta JC. [Evaluation of chronic pain in a population of patients on haemodialysis] Evaluación del dolor crónico en una población de pacientes hemodializado. Rev Soc Esp Enferm Nefrol. 2007;10(2):65-71. Spanish.

46. Rodriguez Calero MA, Sánchez DH, Navarro JG, Amer FJ, Ginesta JC, Llull JS. [Assessment and management of intra-dialysis pain] Evaluación y manejo del dolor intradiálisis. Rev Soc Esp Enferm Nefrol. 2006;9(2):65-70. Spanish

47. Rodriguez Calero MA, Sánchez DH, Navarro JG, Ginesta JC. Dolor intrasesión y dolor crónico en pacientes que reciben hemodiálisis. Metas Enferm. 2009;12(2):12-18. Spanish.

48. Antoniazzi AL, Bigal ME, Bordini CA, Speciali JG. Headache associated with dialysis: the International Headache Society criteria revisited Cephalalgia. 2003;23(2):146-149.

49. Antoniazzi AL, Bigal ME, Bordini CA, Tepper SJ, Speciali JG. Headache and hemodialysis: a prospective study. Headache. 2003;43(2): 99-102.

50. Cristofolini T, Draibe S, Sesso R. Evaluation of factors associated with chronic low back pain in hemodialysis patients. Nephron Clin Pract. 2008;108(4):c249-c255.

51. Jesus A, Oliveira HA, Paixão MO, Fraga TP, Barreto FJ, Valença MM. Clinical description of hemodialysis headache in end-stage renal disease patients. Arq Neuropsiquiatr. 2009;67(4):978-981.

52. Golan E, Haggiag I, Os P, Bernheim J. Calcium, parathyroid hormone, and vitamin D: major determinants of chronic pain in hemodialysis patients. Clin J Am Soc Nephrol. 2009;4(8):1374-1380.

53. Konishiike T, Hashizume H, Nishida K, Inoue H, Nagoshi M. Shoulder pain in long-term haemodialysis patients: a clinical study of 166 patients J Bone Joint Surg Br. 1996;78(4):601-605.

54. Malaki M, Mortazavi FS, Moazemi S, Shoaran M. Insomnia and limb pain in hemodialysis patients: what is the share of restless leg syndrome? Saudi J Kidney Dis Transpl. 2012;23(1):15-20.

55. Aitken E, McLellan A, Glen J, Serpell M, Mactier R, Clancy M. Pain resulting from arteriovenous fistulae: prevalence and impact. Clin Nephrol. 2013;80(5):328-333.

56. Verhallen AM, Kooistra MP, van Jaarsveld BC. Cannulating in haemodialysis: rope-ladder or buttonhole technique? Nephrol Dial Transplant. 2007;22(9):2601-2604.

57. Bourbonnais FF, Tousignant KF. The pain experience of patients on maintenance hemodialysis. Nephrol Nurs J. 2012;39(1):13-19; quiz 20.

58. Milinković M, Zidverc-Trajković J, Sternić N, et al. Hemodialysis headache. Clin Nephrol. 2009;71(2):158-163.

59. Goksel BK, Torun D, Karaca S, et al. Is low blood magnesium level associated with hemodialysis headache? Headache. 2006;46(1): 40-45.
60. Caplin B, Kumar S, Davenport A. Patients' perspective of haemodialysisassociated symptoms. Nephrol Dial Transplant. 2011;26(8):2656-2663.

61. Binik YM, Baker AG, Kalogeropoulos D, et al. Pain, control over treatment, and compliance in dialysis and transplant patients. Kidney Int. 1982;21(6):840-848.

62. Claxton RN, Blackhall L, Weisbord SD, Holley JL. Undertreatment of symptoms in patients on maintenance hemodialysis. J Pain Symptom Manage. 2010;39(2):211-218.

63. Krishnan AV, Phoon RK, Pussell BA, Charlesworth JA, Bostock H, Kiernan MC. Altered motor nerve excitability in end-stage kidney disease. Brain. 2005;128(Pt 9):2164-2174.

64. Laaksonen S, Metsärinne K, Voipio-Pulkki LM, Falck B. Neurophysiologic parameters and symptoms in chronic renal failure. Muscle Nerve. 2002;25(6):884-890.

65. Baumgaertel MW, Kraemer M, Berlit P. Neurologic complications of acute and chronic renal disease. Handb Clin Neurol. 2014;119:383-393.

66. Murtagh FE, Addington-Hall J, Higginson IJ. The prevalence of symptoms in end-stage renal disease: a systematic review. Adv Chronic Kidney Dis. 2007;14(1):82-99.

67. Bay WH, Van Cleef S, Owens M. The hemodialysis access: preferences and concerns of patients, dialysis nurses and technicians, and physicians. Am J Nephrol. 1998;18(5):379-383.

68. Ferrans CE, Powers MJ. Quality of life of hemodialysis patients. ANNA J. 1993;20(5):575-581; discussion 582.

69. Grudzinski A, Mendelssohn D, Pierratos A, Nesrallah G. A systematic review of buttonhole cannulation practices and outcomes. Semin Dial. 2013;26(4):465-475.

70. Wong B, Muneer M, Wiebe N, et al. Buttonhole versus rope-ladder cannulation of arteriovenous fistulas for hemodialysis: a systematic review. Am J Kidney Dis. 2014;64(6):918-936.

71. Atkar RK, MacRae JM. The buttonhole technique for fistula cannulation: pros and cons. Curr Opin Nephrol Hypertens. 2013;22(6):629-636.

72. Bana DS, Yap AU, Graham JR. Headache during hemodialysis. Headache. 1972;12(1):1-14.

73. [No authors listed]. Classification and diagnostic criteria for headache disorders, cranial neuralgias and facial pain. Headache Classification Committee of the International Headache Society. Cephalalgia. 1988;8 Suppl 7:1-96.

74. Headache Classification Subcommittee of the International Headache Society. The International Classification of Headache Disorders: 2nd edition. Cephalalgia. 2004;24 Suppl 1:9-160.

75. Kobrin SM, Berns JS. Quinine - a tonic too bitter for hemodialysisassociated muscle cramps? Semin Dial. 2007;20(5):396-401.

76. Canzanello VJ, Burkart JM. Hemodialysis-associated muscle cramps. Semin Dial. 1992:5(4):299-304.

77. Palmer SC, Craig JC, Jones A, Higgins G, Willis N, Strippoli GF Celebrating 20 years of evidence from the Cochrane Collaboration: what has been the impact of systematic reviews on nephrology? Nephrol Dial Transplant. 2015;30(6):871-877.

78. Alessandri M, Massanti L, Geppetti P, Bellucci G, Cipriani M, Fanciullacci M. Plasma changes of calcitonin gene-related peptide and substance $\mathrm{P}$ in patients with dialysis headache. Cephalalgia. 2006; 26(11):1287-1293.

79. Barrett BJ, Vavasour HM, Major A, Parfrey PS. Clinical and psychological correlates of somatic symptoms in patients on dialysis. Nephron. 1990;55(1):10-15

80. Carreon M, Fried LF, Palevsky PM, Kimmel PL, Arnold RM, Weisbord SD. Clinical correlates and treatment of bone/joint pain and difficulty with sexual arousal in patients on maintenance hemodialysis. Hemodial. 2008;12(2):268-274.

81. Chattopadhyay C, Ackrill P, Clague RB. The shoulder pain syndrome and soft-tissue abnormalities in patients on long-term haemodialysis. Br J Rheumatol. 1987;26(3):181-187.

82. Davison SN, Jhangri GS. The impact of chronic pain on depression, sleep, and the desire to withdraw from dialysis in hemodialysis patients. Journal of Pain \& Symptom Management. 2005;30(5):465-473. 
83. Davison SN, Jhangri GS. Impact of pain and symptom burden on the health-related quality of life of hemodialysis patients. Journal of Pain \& Symptom Management. 2010;39(3):477-485.

84. Elsurer R, Afsar B, Mercanoglu E. Bone pain assessment and relationship with parathyroid hormone and health-related quality of life in hemodialysis. Ren Fail. 2013;35(5):667-672.

85. Er MS, Eroğlu M, Altinel EC, Altinel L. Hemodialysis and pain. The Turkish Nephrology, Dialysis and Transplantation Journal. 2013; 22(2):167-170.

86. Fidan F, Alkan BM, Tosun A, Altunoğlu A, Ardiçoğlu O. Quality of life and correlation with musculoskeletal problems, hand disability and depression in patients with hemodialysis. Int J Rheum Dis. 2016; 19(2):159-166.

87. Gamondi C, Galli N, Schonholzer C, et al. Frequency and severity of pain and symptom distress among patients with chronic kidney disease receiving dialysis. Swiss Med Wkly. 2013;143:w13750.

88. Goksan B, Karaali-Savrun F, Ertan S, Savrun M. Haemodialysis-related headache. Cephalalgia. 2004;24(4):284-287.

89. Harris TJ, Nazir R, Khetpal P, et al. Pain, sleep disturbance and survival in hemodialysis patients. Nephrol Dial Transplant. 2012;27(2): $758-765$.
90. Iacono SA. Chronic Pain in the Hemodialysis Patient Population. Dial Transplant. 2004;33(2):92-101.

91. Khan MA. Frequency of symptomatology in patients on hemodialysis: A single center experience. Rawal Med J. 2012;37(1):24-26.

92. Kimmel PL, Emont SL, Newmann JM, Danko H, Moss AH. ESRD patient quality of life: symptoms, spiritual beliefs, psychosocial factors, and ethnicity. American Journal of Kidney Diseases. 2003;42(4): 713-721.

93. Parfrey PS, Vavasour HM, Henry S, Bullock M, Gault MH. Clinical features and severity of nonspecific symptoms in dialysis patients. Nephron. 1988;50(2):121-128.

94. Shayamsunder AK, Patel SS, Jain V, Peterson RA, Kimmel PL. Sleepiness, sleeplessness, and pain in end-stage renal disease: distressing symptoms for patients. Sem Dialysis. 2005;18(2):109-118.

95. Weisbord SD, Fried LF, Arnold RM, et al. Prevalence, severity, and importance of physical and emotional symptoms in chronic hemodialysis patients. J Am Soc Nephrol. 2005;16(8):2487-2494.

\section{Publish your work in this journal}

Patient Preference and Adherence is an international, peer-reviewed, open access journal that focuses on the growing importance of patient preference and adherence throughout the therapeutic continuum. Patient satisfaction, acceptability, quality of life, compliance, persistence and their role in developing new therapeutic modalities and compounds to optimize clinical outcomes for existing disease states are major areas of interest for the journal. This journal has been accepted for indexing on PubMed Central. The manuscript management system is completely online and includes a very quick and fair peer-review system, which is all easy to use. Visit http://www dovepress.com/testimonials.php to read real quotes from published authors. 